Dear Gustavo:

$I^{\prime}$ $\mathrm{t}$ is inspiring to see that Revista de Medicina has endured for 100 years. It must not have been easy to produce or maintain this journal, particularly during its early days. The fact that it has been continuously in publication for all of that time, and is now curated and accessible online, speaks well for your own dedication and that of your predecessors. This has clearly been a labor of love: love for medicine, and love for the gradual triumph of the human intellect over ignorance, helplessness, and disease.

Medicine brings many thoughts to mind, because of course it is many things. Medicine incorporates compassion, scholasticism, humanism, history, art, and natural science. Few human endeavors come close to this. Medicine of the last 100 years has a somewhat personal meaning to me. It has been the main livelihood of my family for about that length of time. My father's parents and my father himself were physicians. Two of my three sibs are physicians. I am a physician. And there are physicians among our children (no grandchildren yet).

100 years has brought enormous changes to medicine, and I have been directly attentive to these changes over the last 40 years or so. We must respect the great physicians that preceded us, and many of them were truly heroic. Yet we must also admit that at a given time, they could do little more than give comfort as they witnessed the progress of disease. The situation is obviously much different today, and much better. It is mainly medicine we have to thank for this. Objectively, we live much longer lives in better health than ever before. Our expectations about what we can do with our lives has changed as well. For those of us in medicine, this means that we can deliver better care, make further discoveries or inventions, teach what we know, and continue to improve the human condition at an accelerated pace.

I hope to find at least some of the next century of medicine documented in Revista de Medicina. Those who chronicle the challenges, the failures, and the ultimate successes of medicine, and those who practice it today, will surely look forward to each issue.

With best wishes,

\title{
Bruce Beutler
}

